\title{
Management of technical condition of heat and power facilities based on a risk-oriented approach
}

\author{
$R N$ Valiev $^{1}, E V$ Izmaylova $^{1, *}, E S h$ Kharisov $^{2}, M R$ Rotach $^{3}$ and $A V$ Busarov $^{4}$ \\ ${ }^{1}$ Kazan State Power Engineering University, 51, Krasnoselskaya st., Kazan, Russia \\ ${ }^{2}$ LLC «Modern technologies», 41, G. Kamal st., Kazan, Russia \\ ${ }^{3}$ LLC «KER-Avtomatika», 2, Dekabristov str., Kazan, Russia \\ ${ }^{4}$ LLC «Center of industrial safety expertise», 90a Ju.Fucik str., Kazan, Russia
}

\begin{abstract}
Ensuring the uninterrupted production of electric and thermal energy is a priority in the generating equipment operation. Nowadays the management of the equipment state at most of Russia's energy enterprises is based on a system of scheduled preventive maintenance. This system does not allow taking into account the economic component of technological impacts, which, in turn, leads either to "under maintenance" or to "over-servicing" of equipment. All energy companies are faced with the task of optimizing equipment costs, while ensuring the required level of reliability. To solve this problem, production asset management systems are used. The main task of managing production assets is to ensure a balance between equipment costs and the risks of its failure. The result of the implementation of asset management systems is the formation of balanced plans for repairs, replacements, upgrades and maintenance of equipment.
\end{abstract}

\section{Introduction}

In order to improve the technical and economic efficiency of equipment operation, it is necessary to be guided by an investment approach, the essence of which is that any technological impact must be justified both in terms of improving safety, reliability and efficiency of operation, and in terms of economic efficiency of investing financial, material and other resources [1-7].

The current approaches to the assessment of the technical condition and the formation of the volume and range of technological impacts are heterogeneous, often based on a lifetime assessment without taking into account other significant parameters. Generating companies lack of tools to significantly influence the efficiency of managing production assets. The results of this study can be used to develop existing approaches to the management of production assets.

\section{Another section of your paper Approaches to assessing the probability of power equipment failure}

There are known methods for calculating the probability of failure at the following levels:

- calculation and forecasting of resource-determining details reliability indicators;

- calculation and forecasting of functional units reliability indicators;
- calculation and forecasting of the main process equipment reliability indicators.

\section{Approaches to assessing the consequences of power equipment failures}

To determine the effects on total cost of ownership, an analytical method of calculation is used. This method is characterized by the fact that, when calculating the consequences, the current price guides, the accounting system, process charts are used, as well as expert operating experience and accumulated statistical information are considered.

The effects influenced on the change in output are:

- damage from deterioration of technological parameters;

- damage from non-payment of the available capacity of the power plant;

- damage as a result of loss of profits from underproduction of electric and thermal energy;

- damage as a result of loss of profits from undersupply of auxiliary products;

- damage from increasing technological losses due to switching of the consumer's power receiving facility to the backup scheme or disconnection of the generation facility;

- damage from the lack of delivery of electricity services to the consumer's power receiving facility.

\footnotetext{
Corresponding author: evgeniya-izmailova@yandex.ru
} 
The main approaches to asset management known in world practice are discussed in the works [8-12].

At present, there is a lack of practical methods for assessment the effectiveness and choosing the option to increase reliability for the billing period. One of the practical ways of assessment the effectiveness and choosing the option to increase reliability based on wellknown methodological developments is to determine the integral economic effect for the billing period and the payback period of modernization, as applied to individual groups of equipment of power generating companies [13]. The cost-effectiveness of works to improve reliability is directly proportional to the reduction of damage from under-supply of electricity. Difficulties in assessment the efficiency at the planning (design) stage of such work consist in the probabilistic nature of covering the load in the power system, the occurrence of defects leading to power equipment failures, the duration of unplanned downtime for the restoration of productivity.

Asset management methods are improving. Consider the problem of assessment and comparison risk (RiskBased Maintenance - RBM). Equipment may have a high criticality index, have an unsatisfactory value of the state index, be among the priorities for maintenance and repair. However, the costs of its maintenance and repair may exceed the cost estimate of the consequences that would arise from this equipment failure. It is necessary to decide whether to reduce the risk of consequences through repair, or to accept this risk and do not carry out maintenance.

\section{Methods of managing the technical condition of power equipment based on the equipment failure probability and the power output scheme}

The formation of technological impact programs based on the principle of minimizing the cost of the life cycle is achieved through the sequential implementation of the following steps [14]:

Step 1. Analysis and assessment of the current technical condition of the equipment.

Assessment of the technical condition of the equipment is the process of determining the integral indicator of the technical condition (technical condition index) for resource-determining structural elements (nodes) and equipment. The technical condition index is a quantitative assessment of the technical condition of the equipment in the form of a numerical value expressed as a percentage. The results of the step are used to predict the failure probability and determine the remaining life of the equipment.

Step 2. Calculation of the equipment failure probability.

Failure probability prediction is the process of determining the level of the current probability of failure and forecasting the probability of failure during the further operation of equipment for each year for each structural element of equipment and equipment as a whole. The results of the step are used in assessing the current and forecasting level of risks.

Step 3. Assessment of the equipment failures consequences.

At this step, the assessment of the equipment failure impact on the power distribution chain is carried out, which is expressed in determining the value of the reduction in thermal and electrical power generation of thermal power plant. On the basis of the current tariff for thermal and electrical energy, as well as expenses for repair work, it is possible to determine the economic losses from equipment failure. The results of the step are used to assess the current level of risk for each piece of equipment.

Step 4. Assessment of the current level of risks.

At this step, the current level of risks is assessed for each unit of power plant equipment. The results of the step are used in planning the composition of technological impacts and the formation of impact programs.

Step 5. Determining the period of the impacts.

\section{Approbation of method}

Objects are two steam boilers BKZ-420-140-5 (hereinafter referred to as SB).

The following data are used for the calculation: [8];

- Operational characteristics of SB BKZ -420-140-5

- Financial characteristics [15-17];

- Forecast of indexes-deflators and inflation until 2030 (in \%) [18];

- The cost of fuel, heat and electricity for the launch of condensing units [10];

- Values of the duration of boilers inoperability in case of failure of various structural elements [11].

The results of the developed methodology approbation are presented in the figures 1-4.

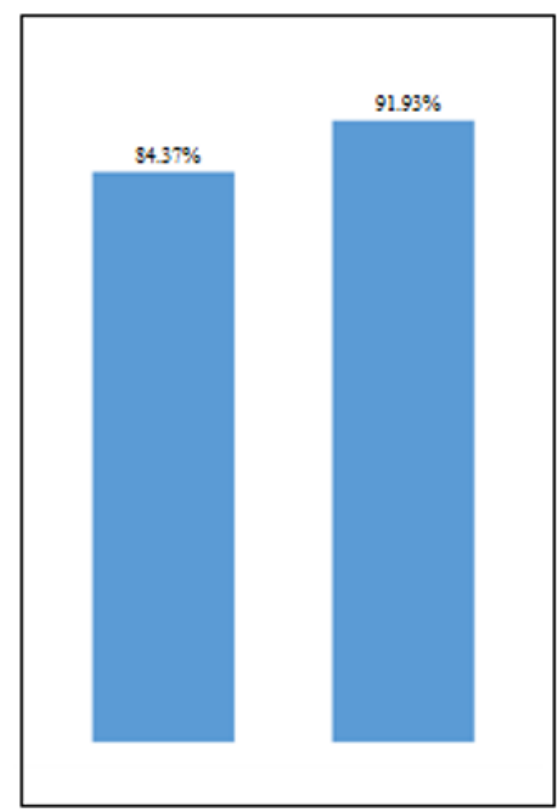

Fig. 1. The results of the technical condition index calculation. 


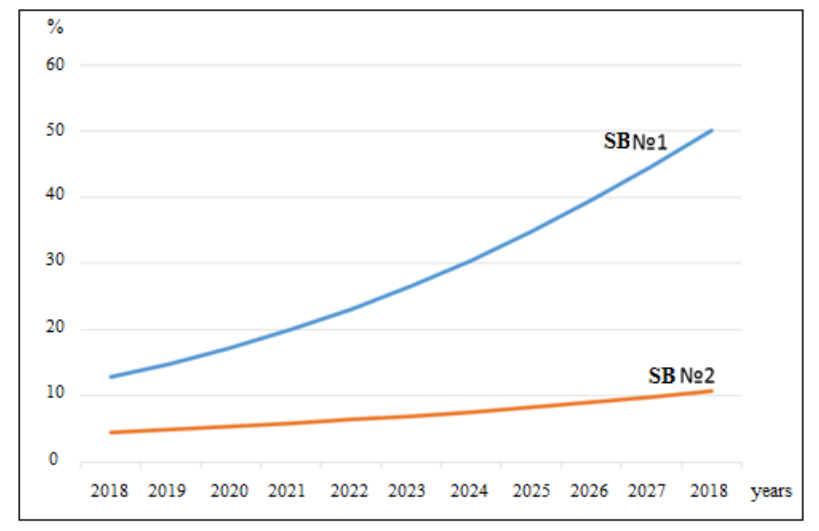

Fig. 2. The results of the failure probability prediction.

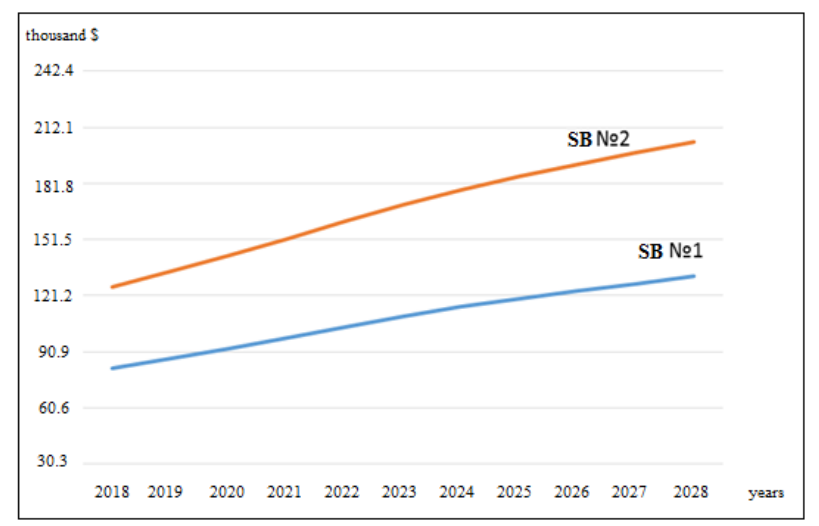

Fig. 3. The results of the damage from failures calculation.

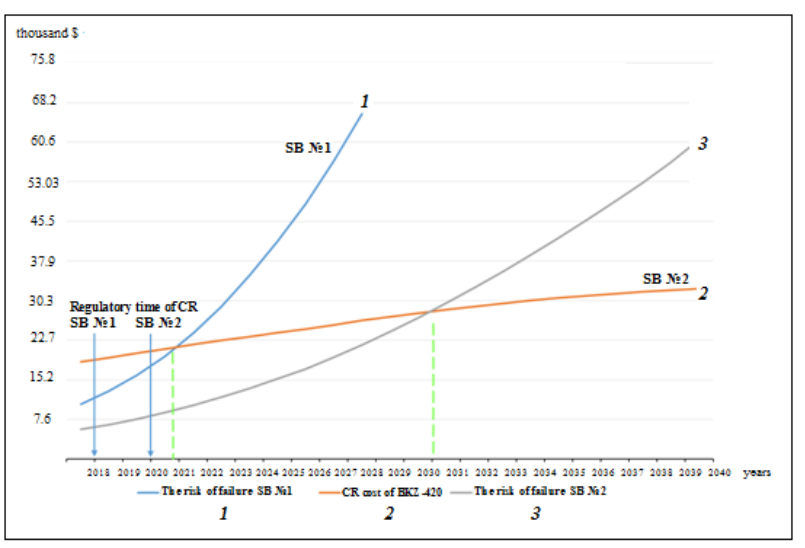

Fig. 4. The risk of failure and the determination of the repair period.

\section{Conclusion}

As a result of calculations for SB No. 1, the optimal repair period is 2022. This date is 3 years later than the regulatory time.

As a result of calculations for SB No. 2, the optimal repair period is 2031. This date is 9 years later than the regulatory time.

The optimal time for the repair is determined considering the technical and production characteristics of the equipment; accordingly, the postponement of the repair period allows to avoid over-servicing of the equipment.

\section{References}

1. A.S. Gorshkov, N.I. Vatin, P.P. Rymkevich, O.O. Kydrevich, Payback period of investments in energy saving Magazine of Civil Engineering, 78(2), 65-75 (2018)

2. V.N. Kabanov, Organizational and technological reliability of the construction process, Magazine of Civil Engineering, 77(1), 59-67 (2018)

3. A.A. Kalyutik, D.V. Grigorieva, A.V. Fedyukhin, O.V. Derevianko, I.G. Akhmetova, Reduction of the technological minimum by bypass method with environmental impact estimation on the example of energy blocks with T-100 and T-250/300-240 turbines, IOP Conference Series: Earth and Environmental Science, 288(1), 012094 (2019)

4. L.V. Plotnikova, R.R. Giniyatov, S.Y. Sitnikov, M.A. Fedorov, R.S. Zaripova, Perfection of the methodology for developing industrial secondary energy generation systems, IOP Conference Series: Earth and Environmental Science, 288(1), 012069 (2019)

5. V.P. Mushchanov, A.N. Orzhekhovskii, A.V. Zubenko, S.A. Fomenko, Refined methods for calculating and designing engineering structures, Magazine of Civil Engineering, 78(2), 101-115 (2018)

6. V.I. Sitas, A.V. Fedyukhin, I.G. Akhmetova, A. Mitrofanov, S.O. Makoev, A. Asadpoori, A.A. Sinitsyn, E.A. Kikot, Assessment of technical and economic efficiency indicators of cogeneration in modern market conditions, International Journal of Civil Engineering and Technology, 10(2), 21062117 (2019)

7. E. Sukhareva, A. Fedyukhin, O. Derevianko, M. Egorov, L. Mukhametova, L. Akhmetova, Optimization of combined heat and power plant operating mode by means of underutilized equipment mothball, IOP Conference Series: Earth and Environmental Science, 288(1), 012122 (2019)

8. The reporting form of the power engineering facility in accordance with Order 340 (Appendix 73. Section 2 Table 1 Main technical data of power steam boilers and waste heat boilers)

9. Official website of the Ministry of Economic Development of the Russian Federation [Electronic resource]

http://economy.gov.ru/minec/activity/sections/macr o/prognoz/doc20130325_06

10. RD 34.08.552-95 Methodical instructions for writing a report of a power plant and a joint-stock company of energy and electrification on the thermal efficiency of equipment

11. S.A. Belyayev, V.V. Litvak, S.S. Solod, Reliability of TPP thermal power equipment, 218 (2018)

12. I.G. Akhmetova, N.D. Chichirova, Application of SAW method for multiple-criteria comparative analysis of the reliability of heat supply 
organizations, Thermal Engineering, 63(14), 10161024 (2016)

13. I.G. Belov, Management of production assets in the energy sector: the quality of repairs and reliability maintenance, Power Plants, 3 (2005)

14. Ye.P. Grabchak, Monograph. Digital transformation of electric power, ISBN 978-54365-3063-5, 338 (2018)

15. Ernst \& Young LLC - Assessment and consulting services Review of the Russian electric power industry [Electronic resource] https://www.ey.com/Publication/vwLUAssets/EYpower-market-russia-2018/\$File/EY-power-marketrussia-2018.pdf

16. I.A. Dolmatov, Ye.V. Yarkin, Electric power industry of Russia: Main performance indicators and development trends [Electronic resource] https://ipcrem.hse.ru/mirror/pubs/share/219091356 (2015)

17. Official Unified Interdepartmental Informational Statistical System [Electronic resource] https://www.fedstat.ru/indicator/33926

18. Official Ministry of Economic Development of the Russian Federation [Electronic resource] http://economy.gov.ru/minec/activity/sections/macr o/prognoz/doc20130325_06 